\title{
Triazavirine supramolecular complexes as modifiers of the peptide oligomeric structure
}

\author{
Alexey V. Shvetsov ${ }^{1,2}$, Yana A. Zabrodskaya ${ }^{3}$, Peter A. Nekrasov ${ }^{3}$, \\ and Vladimir V. Egorov ${ }^{1,3,4}$ \\ ${ }^{1}$ Petersburg Nuclear Physics Institute named by B.P.Konstantinov \\ of National Research Centre "Kurchatov Institute", 188300, Orlova \\ Roscha, Gatchina, Russia \\ ${ }^{2}$ Peter the Great Saint-Petersburg Polytechnic University, 194064, \\ 29, Politekhnicheskaya, St. Petersburg, Russia \\ ${ }^{3}$ Research Institute of Influenza, Ministry of Healthcare of the \\ Russian Federation, 197376, 15/17, Prof. Popova, St. Petersburg, \\ Russia \\ ${ }^{4}$ Federal State Budgetary Scientific Institution "Institute of \\ Experimental Medicine" 197376, 12, Akad. Pavlova, St. \\ Petersburg, Russia
}

\begin{abstract}
In this study we present molecular dynamics simulations of the antiviral drug triazavirine, that affects formation of amyloid-like fibrils of the model peptide (SI). According to our simulations, triazavirine is able to form linear supramolecular structures which can act as shields and prevent interactions between SI monomers. This model, as validated by simulations, provides an adequate explanation of triazavirine's mechanism of action as it pertains to SI peptide fibril formation.
\end{abstract}

\section{Introduction}

Conformational changes play a significant role both in normal protein functioning and in disease. Amyloid-like fibril formation is the process that underlies the pathogenesis of conformational diseases. Such fibrils are resistant to proteolytic enzymes, as well as to chemical and physical influences [16]. Amyloid-like oligomers can also act as signal transducers in health and in disease [19]. Agents that affect protein oligomer formation can be used as fibrillogenesis inhibitors, or as signal transduction regulators. In our previous studies [6], we demonstrated the effect of triazavirine (a guanine nucleotide analog [11], TZV, Figure 
1) on GDIRIDIRIDIRG peptide (self-complementary ionic, SI) fibril dissociation. Transmission electronic microscopy and small-angle neutron scattering were effectively used to study the interaction.

The SI peptide is comprised of an ionic, self-complementary motif (iSCM). This motif was first identified in small heat shock proteins, crystalline oligomeric complexes [7], and in peptides with labile secondary structures [2]. The interaction between these polypeptides occurs at a site where antiparallel-oriented iSCMs monomers (on opposing polypeptides) interact.

Electrostatic attraction between monomers, and zipper-like hydrophobic interactions between oligomers, are the two major driving forces allowing iSCM to successfully complete the self-organization process [4], [10]. In previous studies [6], we hypothesized that triazavirine, due to its status as a guanosine analogue, may have a tendency to interact with arginine [12]. Triazavirine's interaction with iSCM most likely involves a shielding of arginine's positive charge by the drug, and a modification of the motif's overall charge. The modified local charge environment shifts the balance towards protein aggregate dissociation and towards monomer formation (via repulsion). Molecules with similar anti-fibrillogenic mechanisms of action have been described previously [15, 14]. In this study, we examined triazavirine with molecular dynamics simulations in terms of its action on SI peptide fibrils.

\section{Materials and Methods}

\section{Modelling of the TZV system}

TZV modelling was accomplished using the Avogadro[8] software package. The topology of TZV for GROMACS was generated using ACPYPE[17] and antechamber from Ambertools[18]. Two systems with 32 and 320 TZV molecules in $1000 \mathrm{~nm}^{3}$ boxes $(10 \times 10 x 10 \mathrm{~nm})$ were created using gmx insert-mol.

\section{Modelling of the SI peptide system}

Initial conformations of GDIRIDIRIDIRG peptide were constructed as unfolded states using Pymol[5]. After that, 16 GDIRIDIRIDIRG peptide chains were inserted into $1000 \mathrm{~nm}^{3}$ box $(10 \times 10 \times 10 \mathrm{~nm})$ in random orientations using gmx insert-mol. In models which included TZV in addition to 16 GDIRIDIRIDIRG molecules, $320 \mathrm{TZV}$ molecules were inserted with random orientations using gmx insert-mol.

\section{Molecular dynamics}

All MD simulations were performed in the GROMACS [1,3] software package using amber99sb-ildn[13] force field for peptides, and tip3p[9] model for explicit water. Simulated systems were around $140 \mathrm{k}$ atoms in size including explicit solvent shell and $50 \mathrm{mM} \mathrm{NaCl}$ to neutralize charges on peptides (and TZV, if present in the model). Solvent shell thickness was at least $2.5 \mathrm{~nm}$. The 
systems were equilibrated using a two step protocol. During the first step, the system was equilibrated for $5 \mathrm{~ns}$ with all heavy, non-solvent atoms restrained to their initial positions using NPT ensemble. During the second step, the system was equilibrated without restraines for $10 \mathrm{~ns}$ (starting from the last frame of the previous step). After two equilibration stages, a 500 ns trajectory was simulated with a time step of 2 fs. A Neighbour search was performed every 50 steps. The PME algorithm was used for modeling electrostatic and Van der Waals interactions with a cut-off of $1.2 \mathrm{~nm}$. Temperature coupling was done with the Nose-Hoover algorithm at 310K. Pressure coupling was done with the Parrinello-Rahman algorithm for 1 bar.

\section{Quasi-elastic light scattering}

Quasi-elastic light scattering (QLS) measurements were performed using QLSspectrometer LCS-03 (Intox, Russia). Spectra analysis was performed with the spectrometer software using an "rod-like" model of scattering objects.

\section{Results and discussion}

Molecular dynamics simulations showed that the SI peptide in solution is prone to the formation of aggregates. Figure 2a shows the final condition of 16 SI peptide molecules after $500 \mathrm{~ns}$ of simulation.

Interestingly, the molecular dynamics simulations of triazavirin in solution also showed that it has a tendency to form linear supramolecular complexes at concentrations above $10 \mathrm{mg} / \mathrm{ml}$. Figure 3 presents the results of a simulation of an ensemble of 32 triazavirin molecules (equivalent to $11 \mathrm{mg} / \mathrm{ml}$ ) and 320 triazavirin molecules (equivalent to $110 \mathrm{mg} / \mathrm{ml}$ ) in a $1000 \mathrm{~nm}^{3}$ cell.

It should be noted that during in-vitro measurements using QLS in triazavirin solutions (after filtering), we also observed the presence of light-scattering structures at concentrations above $2 \mathrm{mg} / \mathrm{ml}$. Figure 4 shows the results of QLS of triazavirin solutions at concentrations of $2 \mathrm{mg} / \mathrm{ml}$ and $20 \mathrm{mg} / \mathrm{ml}$.

In QLS experiments, the formation of sub-microscopic particles in triazavirin solutions was observed. The triazavirin critical concentration in solution (below which particle formation was not observed) was $2 \mathrm{mg} / \mathrm{ml}$. We performed measurements immediately after dilution, after 30 minutes, and after 60 minutes. Particle formation dynamics did not depend on the tested concentrations. Immediately after preparation, a fraction of particles with a hydrodynamic radius of about $100-200 \mathrm{~nm}$ was observed. This can be explained as dissolution of the drug, in its crystalline particle form, into aqueous solution. Then, at the next measurement time point (30 minutes), the fraction was split into 2 subfractions. Further changes in fraction size distributions (after 60 minutes) were not observed. The hydrodynamic radius of the particles at concentrations of 2 $\mathrm{mg} / \mathrm{ml}$ were $75-90$ and 1000-1500 $\mathrm{nm}$ for concentration of $2 \mathrm{mg} / \mathrm{ml}$, and 90-250 and $600-1500$ for concentration of $20 \mathrm{mg} / \mathrm{ml}$. 
Thus, the QLS experiments have shown triazavirin's ability to form supramolecular complexes. In order to study the influence of such complexes on the formation of fibrils in solution, molecular dynamics simulations of the SI peptide in the presence of a 10-fold molar excess of triazavirin were performed.

Figure $2 \mathrm{~b}$ shows the final state of 16 SI peptide molecules in the presence of 320 triazavirin molecules after $500 \mathrm{~ns}$ simulation.

A comparison of pairwise distances between the peptide molecules' center of mass for SI with and without TZV reveals an increase in the average value of pairwise distances. In Figure 5 there is a colored diagram of such a comparision.

Figure 6 shows that rod-like TZV supramolecular complexes act as shields and prevent peptide-peptide interaction. In Figure 7 there is a histogram of mean center of mass pairwise distances between SI peptide and TZV molecules. It showed that some of TZV molecules have stable positions near SI peptide monomers during the last $250 \mathrm{~ns}$ of simulation.

In silico simulation shows that triazavirine, at $10 \mathrm{mg} / \mathrm{ml}$ and higher concentrations, can form supra-molecular linear structures. The presence of such structures in solution was detected by QLS, and the results are consistent with our previous small-angle neutron scattering data. According to our simulations, these linear triazavirine supramolecular structures act as shields and prevent interactions between SI monomers. Our model, as validated by simulations, provides an adequate explanation of triazavirine's mechanism of action as it pertains to SI peptide fibril formation.

\section{Conclusion}

Thus, the molecular dynamics simulation shows that, apparently, in addition to interactions between triazavirin molecules and side chains of arginines (described in $[6,16])$, interactions between peptide molecules and triazavirin supramolecular complexes can occur.

\section{Acknowledgments}

The results of the work were obtained using computational resources of Department of Information and Computational Technologies of the St. Petersburg State Polytechnic University (http://www.spbstu.ru). We thanks Mr. Edward Ramsay for the help in writing the manuscript and Dr. D. V. Lebedev (DMRB PNPI NRC KI) for the fruitful discussion of the experiments. This study was supported by the Russian Foundation for Basic Research, project no 14-24-01103 ofi_m.

\section{References}

[1] M. J. Abraham, T. Murtola, R. Schulz, S. P?ll, J. C. Smith, B. Hess, and E. Lindahl. GROMACS: High performance molecular simulations through 
multi-level parallelism from laptops to supercomputers. SoftwareX, 1-2: 19-25, sep 2015. doi: 10.1016/j.softx.2015.06.001.

[2] M. Altman, P. Lee, A. Rich, and S. Zhang. Conformational behavior of ionic self-complementary peptides. Protein science : a publication of the Protein Society, 9(6):1095-105, jun 2000. doi: 10.1110/ps.9.6.1095.

[3] H. Berendsen, D. van der Spoel, and R. van Drunen. GROMACS: A message-passing parallel molecular dynamics implementation. Computer Physics Communications, 91(1-3):43-56, sep 1995. doi: 10.1016/00104655(95)00042-E.

[4] G. D'Auria, M. Vacatello, L. Falcigno, L. Paduano, G. Mangiapia, L. Calvanese, R. Gambaretto, M. Dettin, and L. Paolillo. Self-assembling properties of ionic-complementary peptides. Journal of Peptide Science, 15(3): 210-219, mar 2009. doi: 10.1002/psc.1083.

[5] W. L. Delano. The PyMOL Molecular Graphics System, 2002. URL http://www . pymol.org.

[6] V. V. Egorov, Y. A. Zabrodskaya, D. V. Lebedev, and A. N. Gorshkov. Structural features of the ionic self-complementary amyloidogenic peptide. Journal of Physics: Conference Series, in press(1):1-7, may 2017. doi: 10.1088/1742-6596/848/1/012022.

[7] P. N. Farnsworth and K. Singh. Self-complementary motifs (SCM) in alphacrystallin small heat shock proteins. FEBS Letters, 482(3):175-179, oct 2000. doi: 10.1016/S0014-5793(00)02051-2.

[8] M. D. Hanwell, D. E. Curtis, D. C. Lonie, T. Vandermeerschd, E. Zurek, and G. R. Hutchison. Avogadro: An advanced semantic chemical editor, visualization, and analysis platform. Journal of Cheminformatics, 4(8):17, 2012. doi: 10.1186/1758-2946-4-17.

[9] W. L. Jorgensen, J. Chandrasekhar, J. D. Madura, R. W. Impey, and M. L. Klein. Comparison of simple potential functions for simulating liquid water. The Journal of Chemical Physics, 79(2):926-935, jul 1983. doi: 10.1063/1.445869.

[10] M. Kabiri, I. Bushnak, M. T. McDermot, and L. D. Unsworth. Toward a mechanistic understanding of ionic self-complementary peptide selfassembly: Role of water molecules and ions. Biomacromolecules, 14(11): 3943-3950, nov 2013. doi: 10.1021/bm401077b.

[11] I. Karpenko, S. Deev, O. Kiselev, V. Charushin, V. Rusinov, E. Ulomsky, E. Deeva, D. Yanvarev, A. Ivanov, O. Smirnova, S. Kochetkov, O. Chupakhin, and M. Kukhanova. Antiviral Properties, Metabolism, and Pharmacokinetics of a Novel Azolo-1,2,4-Triazine-Derived Inhibitor of Influenza A and B Virus Replication. Antimicrobial Agents and Chemotherapy, 54 (5):2017-2022, may 2010. doi: 10.1128/AAC.01186-09. 
[12] G. Lancelot, R. Mayer, and C. Hélène. Models of interaction between nucleic acids and proteins Hydrogen bonding of arginine with nucleic acid bases, phosphate groups and carboxylic acids. BBA Section Nucleic Acids And Protein Synthesis, 564(2):181-190, sep 1979. doi: 10.1016/00052787(79)90217-X.

[13] K. Lindorff-Larsen, S. Piana, K. Palmo, P. Maragakis, J. L. Klepeis, R. O. Dror, and D. E. Shaw. Improved side-chain torsion potentials for the Amber ff99SB protein force field. Proteins: Structure, Function, and Bioinformatics, 78(8):NA-NA, jun 2010. doi: 10.1002/prot.22711.

[14] E. Lump, L. M. Castellano, C. Meier, J. Seeliger, N. Erwin, B. Sperlich, C. M. Stürzel, S. Usmani, R. M. Hammond, J. Von Einem, G. Gerold, F. Kreppel, K. Bravo-Rodriguez, T. Pietschmann, V. M. Holmes, D. Palesch, O. Zirafi, D. Weissman, A. Sowislok, B. Wettig, C. Heid, F. Kirchhoff, T. Weil, F. G. Klärner, T. Schrader, G. Bitan, E. Sanchez-Garcia, R. Winter, J. Shorter, and J. Munch. A molecular tweezer antagonizes seminal amyloids and HIV infection. eLife, 4 (AUGUST2015), aug 2015. doi: 10.7554/eLife.05397.

[15] J. A. Martellini, A. L. Cole, N. Venkataraman, G. A. Quinn, P. Svoboda, B. K. Gangrade, J. Pohl, O. E. Sorensen, and A. M. Cole. Cationic polypeptides contribute to the anti-HIV-1 activity of human seminal plasma. The FASEB Journal, 23(10):3609-3618, oct 2009. doi: 10.1096/fj.09-131961.

[16] J. D. Sipe, M. D. Benson, J. N. Buxbaum, S.-i. Ikeda, G. Merlini, M. J. M. Saraiva, and P. Westermark. Nomenclature 2014: Amyloid fibril proteins and clinical classification of the amyloidosis. Amyloid : the international journal of experimental and clinical investigation : the official journal of the International Society of Amyloidosis, 21(4):221-4, dec 2014. doi: 10.3109/13506129.2014.964858.

[17] A. W. Sousa da Silva and W. F. Vranken. ACPYPE - AnteChamber PYthon Parser interfacE. BMC Research Notes, 5(1):367, 2012. doi: 10.1186/1756-0500-5-367.

[18] J. Wang, R. M. Wolf, J. W. Caldwell, P. A. Kollman, and D. A. Case. Development and testing of a general Amber force field. Journal of Computational Chemistry, 25(9):1157-1174, jul 2004. ISSN 01928651. doi: $10.1002 /$ jcc.20035.

[19] H. Wu. Higher-order assemblies in a new paradigm of signal transduction. Cell, 153(2):287-292, apr 2013. doi: 10.1016/j.cell.2013.03.013. 
bioRxiv preprint doi: https://doi.org/10.1101/150664; this version posted June 16, 2017. The copyright holder for this preprint (which was not certified by peer review) is the author/funder, who has granted bioRxiv a license to display the preprint in perpetuity. It is made available under aCC-BY-ND 4.0 International license.

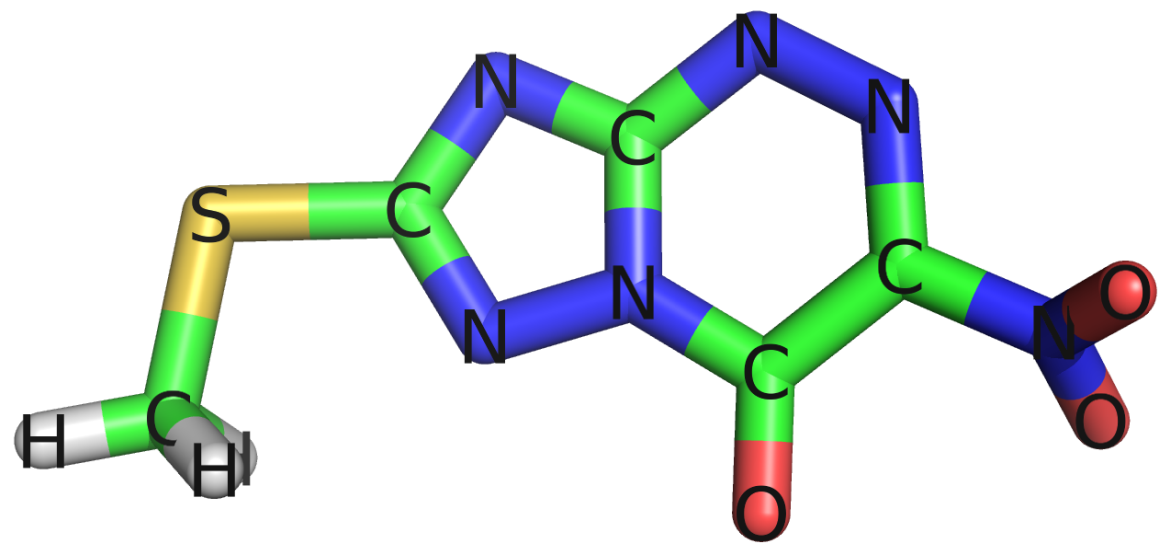

Figure 1: Structure of triazavirine (a guanine nucleotide analog [11], TZV)
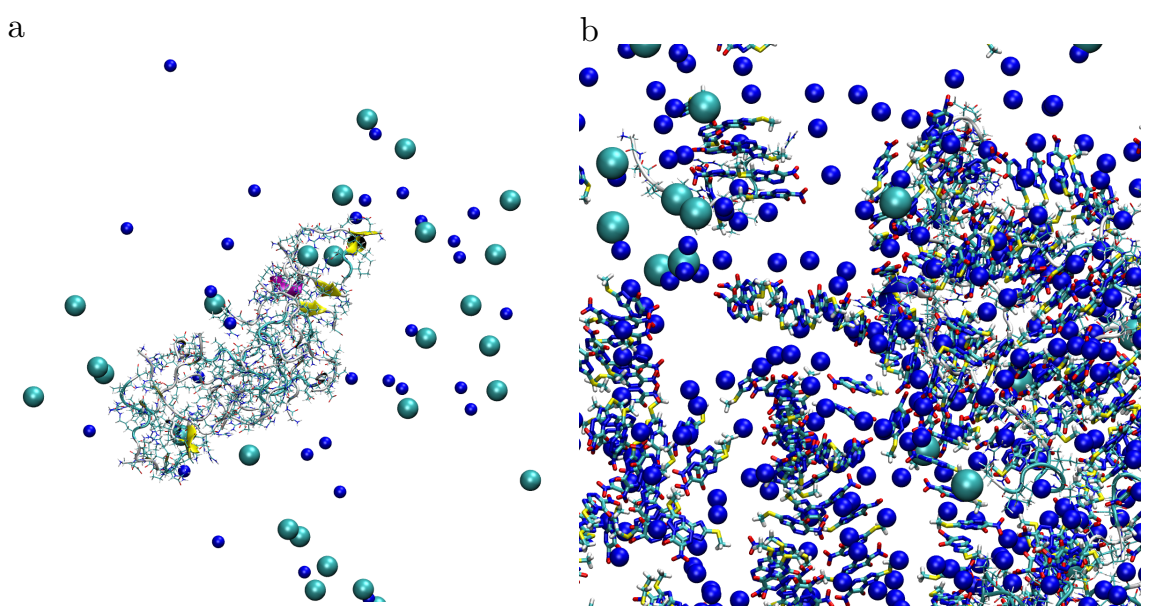

Figure 2: Final state of a 500 ns molecular dynamics simulation of 16 SI peptide molecules in solution (a) and 16 SI peptide molecules in solution with 20-fold molar excess of triazavirine (b) 


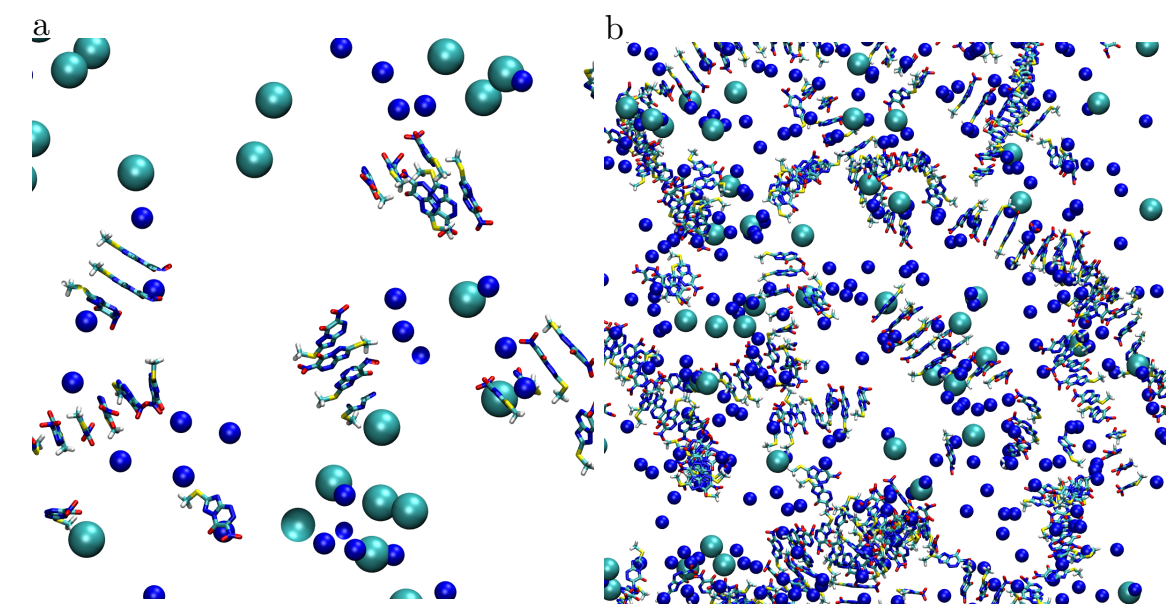

Figure 3: The final state of a 500 ns molecular dynamics simulation of 32 (a) and 320 (b) triazavirin molecules in solution. There is a tendency for the formation of linear structures.

a

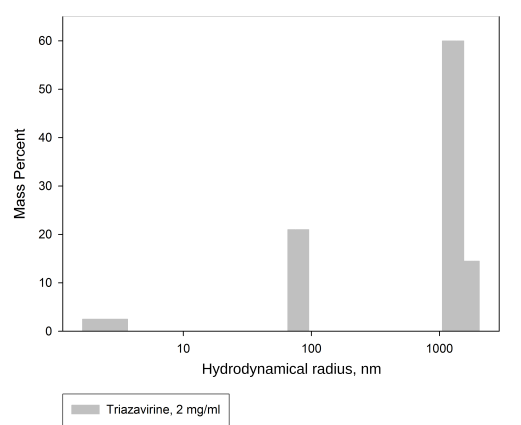

$\mathrm{b}$

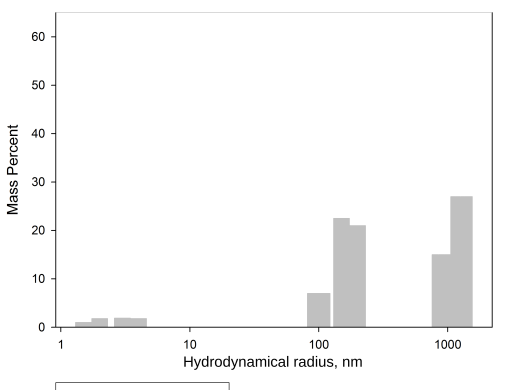

Triazavine, $20 \mathrm{mg} / \mathrm{ml}$

Figure 4: Results of QLS measurements of triazavirin solutions at $2 \mathrm{mg} / \mathrm{ml}$ (a) and $20 \mathrm{mg} / \mathrm{ml}$ (b) concentrations. 

aCC-BY-ND 4.0 International license.

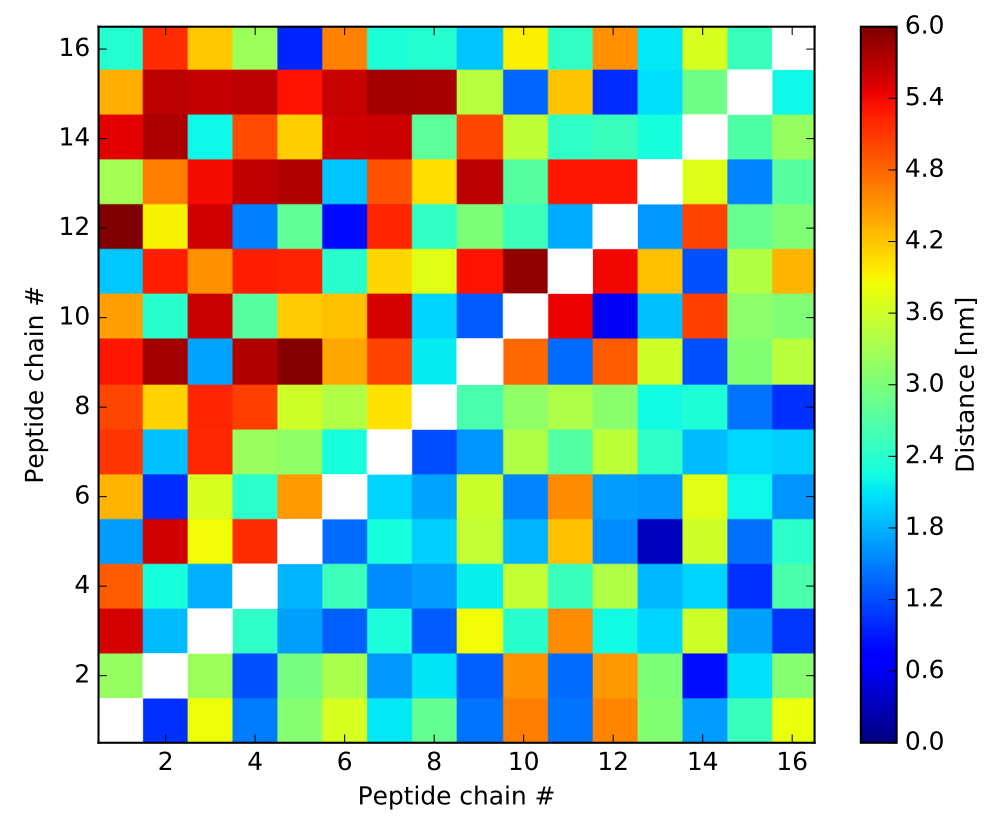

Figure 5: Diagram of pairwise distances between SI peptide molecules in the process of simulation in the presence (above diagonal) or absence (below diagonal) of 20 -fold triazavirine excess 
bioRxiv preprint doi: https://doi.org/10.1101/150664; this version posted June 16, 2017. The copyright holder for this preprint (which was not certified by peer review) is the author/funder, who has granted bioRxiv a license to display the preprint in perpetuity. It is made available under aCC-BY-ND 4.0 International license.

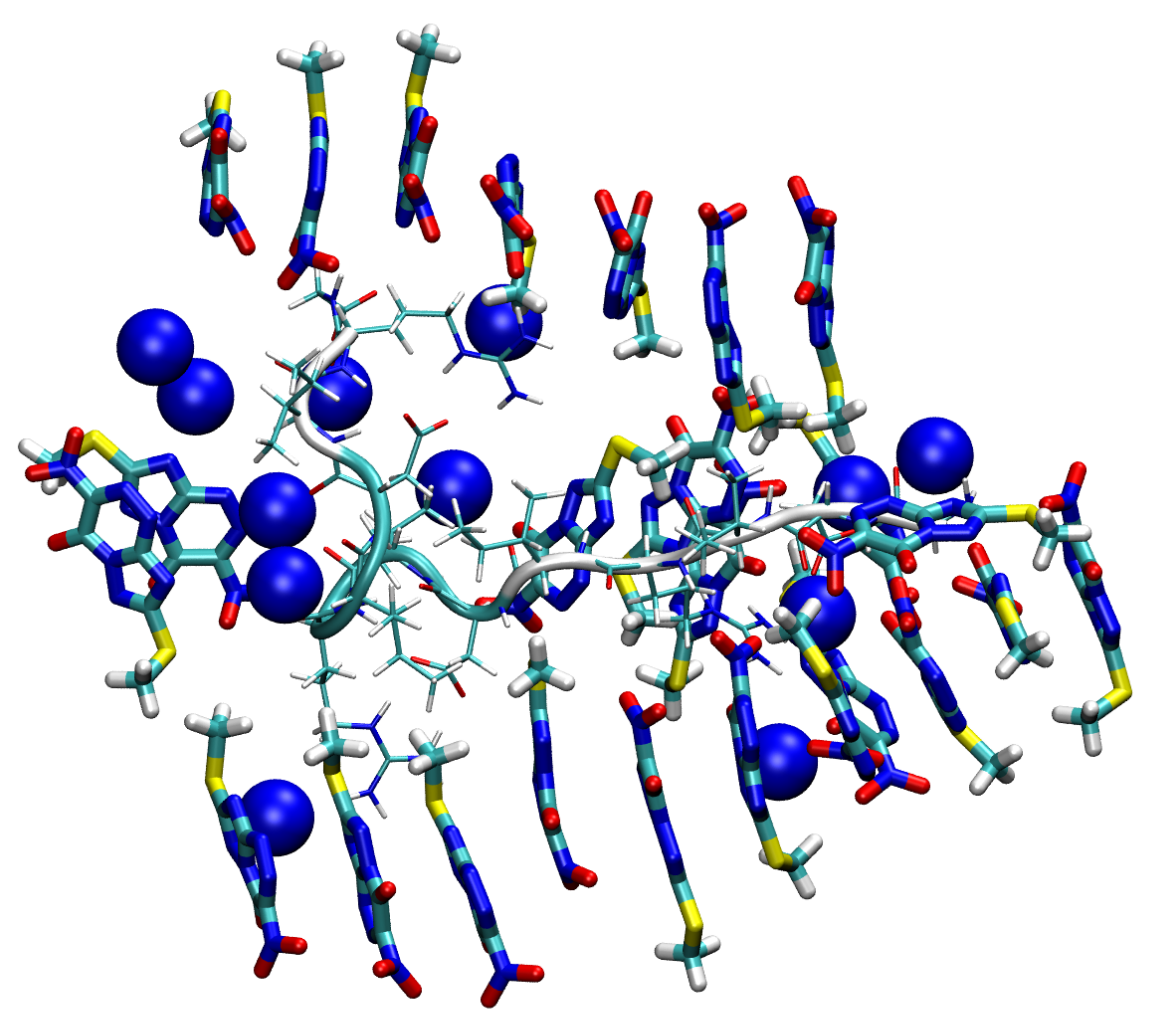

Figure 6: Interactions between SI and TZV supra-molecular complexes 
bioRxiv preprint doi: https://doi.org/10.1101/150664; this version posted June 16, 2017. The copyright holder for this preprint (which was not certified by peer review) is the author/funder, who has granted bioRxiv a license to display the preprint in perpetuity. It is made available under aCC-BY-ND 4.0 International license.

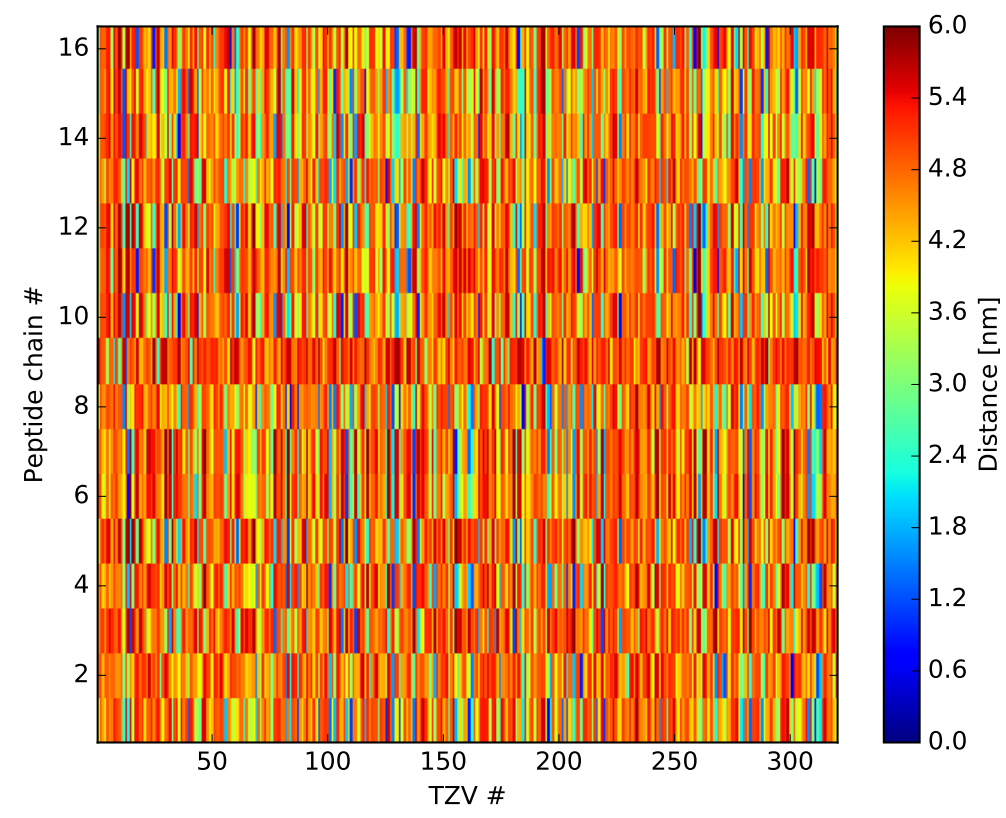

Figure 7: Diagram of mean pairwise distances between SI peptide molecules and TZV molecules during last $250 \mathrm{~ns}$ of simulation 